\title{
THE USE OF THE INSULIN ZINC SUSPENSIONS IN DIABETIC CHILDREN
}

\author{
BY \\ ARTHUR W. FERGUSON \\ From the Department of Child Health, University of Bristol
}

(RECEIVED FOR PUBLICATION MAY 10, 1954)

It is generally conceded that in children there is greater difficulty in achieving good control of diabetes with one daily insulin injection than there is in adults. At the same time it is in children especially that the need for fewer daily injections is felt.

The recent introduction of the new long-acting insulin zinc suspension (IZS) by Hallas-Møller (Hallas-Møller, Jersild, Petersen and Schlichtkrull, 1952) at the Novo Laboratories, Denmark, raised the two questions of whether this preparation could be used with success in children, and whether it offered advantages over the other long-acting insulins. The amorphous form of IZS (Novo 'semilente') is said to act for 12 to 16 hours after injection, and the crystalline form (Novo 'ultralente') for more than 24 hours. Novo 'lente' is a stable mixture containing $30 \%$ amorphous and $70 \%$ crystalline IZS. Reports on the use of IZS in adult diabetics have so far tended to be mainly favourable (FitzGerald, Thorn and Malins, 1954; Hallas-Møller et al., 1952; Lawrence and Oakley, 1953; Murray and Wilson, 1953; Nabarro and Stowers, 1953; Venning, 1954). Lawrence (1954) states that children have responded well. When IZS (Novo) became available to us in August, 1953, we decided to conduct a trial in diabetic children. The first aim was to assess its practical value by clinical standards, regarding satisfactory clinical control as the most important criterion, and blood sugar studies primarily as an aid to achieving this. The standards for satisfactory clinical control were that the children should, while leading unrestricted lives, feel well and be free of all symptoms, with an upward weight trend. At the same time the urine should remain free of acetone, and a daily urinary sugar loss of not more than $10 \%$ of the dily carbohydrate intake was considered desirable. In this paper classification of clinical control has been restricted to two categories. Wherever control fell below the 'satisfactory' standard (as defined above), it has been classed as 'poor'.

A secondary aim of the study was to compare, by simple clinical and biochemical criteria, the control obtainable respectively with two daily injections of soluble insulin and one of insulin zinc suspension.

\section{Methods}

These studies were made at the Royal Hospital for Sick Children, Bristol (11 cases), and the Royal United Hospital, Bath (four cases).

The children were admitted to hospital but were allowed, so far as was possible, to lead lives of unrestricted activity, and regularly attended the physiotherapy department and handwork room. Each child was kept on a diet of constant calorie value, with approximately three parts of carbohydrate to one each of protein and fat. The total calorie content was based on the age of the child, after Collens and Boas (1946).

The main meals were given at 8 a.m., mid-day, 4 p.m., and 7.30 p.m. They were of roughly equal calorie value, except in the case of the smaller children who were given only milk and biscuits in bed at 7.30 p.m. All the children had a cup of milk at 10 a.m.

Urines were tested four-hourly for sugar and acetone by Benedict's and Rothera's methods. The total 24-hour urinary sugar output was measured three times weekly and on days when blood sugar studies were made. Insulin injections were given immediately before breakfast (8 a.m.) and at 7.30 p.m.

The following programme was adhered to whenever circumstances allowed. As a first step where necessary the 'old' cases were re-stabilized without changing the insulin preparation. When adequate control was established, capillary blood sugar levels were estimated over a 24- or 48-hour period by King and Garner's colorimetric method. Samples were taken at 8 a.m., 12 noon, 4 p.m., 7.30 p.m. and 11 p.m. or midnight. Treatment was then changed to a single injection of insulin zinc suspension, given at 8 a.m., starting with the same total number of units previously required each day. This dose was subsequently adjusted, as indicated by the results of urine testing. Usually some increase in total dose was necessary (vide infra). As soon as control again seemed satisfactory, 24- or 48-hour blood sugar studies were repeated. In most of the children a number of blood sugar studies were made with different doses and combinations of the Novo preparations of IZS. 
TABLE 1

DETAILS OF 15 DIABETIC CHILDREN TREATED WITH IZS AND AN ASSESSMENT OF THE CONTROL ACHIEVED

\begin{tabular}{|c|c|c|c|c|c|c|c|c|c|c|c|}
\hline \multirow{13}{*}{ 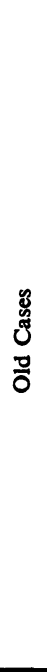 } & \multirow{4}{*}{$\begin{array}{r}\text { Case } \\
\text { No. } \\
1 \\
2\end{array}$} & \multirow{4}{*}{$\begin{array}{c}\text { Age } \\
7 \frac{1}{2} \\
8\end{array}$} & \multirow{4}{*}{$\begin{array}{c}\text { Sex } \\
\text { F } \\
\text { F }\end{array}$} & \multirow{4}{*}{$\begin{array}{l}\begin{array}{c}\text { Duration of } \\
\text { Diabetes }\end{array} \\
2 \text { years } \\
9 \text { months }\end{array}$} & \multirow{4}{*}{$\begin{array}{c}\begin{array}{c}\text { Estimate of } \\
\text { Recent } \\
\text { Control }\end{array} \\
\text { Satisfactory } \\
\text { Satisfactory }\end{array}$} & \multicolumn{2}{|c|}{$\begin{array}{l}\text { Insulin Before } \\
\text { Transfer }\end{array}$} & \multirow{2}{*}{\multicolumn{2}{|c|}{$\begin{array}{c}\text { Optimum } \\
\text { Type and } \\
\text { Dose of IZS } \\
\end{array}$}} & \multirow{4}{*}{$\begin{array}{l}\begin{array}{l}\text { Duration of } \\
\text { 'Follow-up' }\end{array} \\
5 \text { months* } \\
5 \text { months }\end{array}$} & \multirow{4}{*}{$\begin{array}{c}\begin{array}{c}\text { Estimate of } \\
\text { Control with } \\
\text { IZS }\end{array} \\
\text { Satisfactory } \\
\text { Satisfactory }\end{array}$} \\
\hline & & & & & & a.m. & p.m. & & & & \\
\hline & & & & & & SI. 25 & SI. 18 & Lente & 50 & & \\
\hline & & & & & & SI. 28 & SI. 21 & $\left\{\begin{array}{l}\text { Semilente } \\
\text { Lente }\end{array}\right.$ & $\begin{array}{l}30 \\
20\end{array}$ & & \\
\hline & 3 & $4 \frac{1}{2}$ & F & 6 months & Satisfactory & $\left\{\begin{array}{lr}\text { SI. } & 11 \\
\text { PZZI. } & 5\end{array}\right.$ & SI. 12 & Lente & 30 & 5 months* & Satisfactory \\
\hline & 4 & $9 \frac{1}{2}$ & $\mathbf{M}$ & $2 \frac{1}{2}$ years & Poor & SI. $\quad 30$ & SI. 16 & Lente & 60 & 4 months & Poor \\
\hline & 5 & $14 \frac{1}{2}$ & $\mathbf{M}$ & $2 \frac{1}{2}$ years & Poor & $\begin{cases}\text { SII. } & 40 \\
\text { PZII. } & 15\end{cases}$ & SI. 20 & Lente & 100 & 5 months & Satisfactory \\
\hline & 6 & 15 & $\mathbf{F}$ & 10 years & Poor & SI. 40 & SI. 40 & Lente & 100 & $2 \frac{1}{2}$ months & Poor \\
\hline & 8 & $11 \frac{1}{2}$ & $\mathbf{M}$ & 9 months & Satisfactory & SI. 16 & SI. 18 & $\left\{\begin{array}{l}\text { Semilente } \\
\text { Lente }\end{array}\right.$ & $\begin{array}{l}10 \\
24\end{array}$ & 5 months & Satisfactory \\
\hline & 9 & $6 \frac{1}{2}$ & $\mathbf{F}$ & $2 \frac{1}{2}$ years & Satisfactory & SI. 18 & SI. 16 & Lente & 32 & 4 months & Satisfactory \\
\hline & 12 & 10 & $\mathbf{M}$ & 4 years & Satisfactory & SI. 32 & SI. 26 & Lente & 72 & 5 months* & Satisfactory \\
\hline & 13 & 14 & F & 6 years & Poor & SI. 24 & SI. 14 & - & & - & Poor \\
\hline & 14 & $6 \frac{1}{2}$ & $\mathbf{M}$ & $3 \frac{1}{2}$ years & Poor & $\begin{cases}\text { SI. } & 8 \\
\text { PZII. } & 8 \\
\end{cases}$ & - & Lente & 30 & 2 months & Satisfactory \\
\hline & 7 & 12 & $\mathbf{M}$ & 3 weeks & - & & & $\left\{\begin{array}{l}\text { Lente } \\
\text { Ultralente }\end{array}\right.$ & $\begin{array}{l}4 \\
4\end{array}$ & 6 months & Satisfactory \\
\hline రू & 10 & 6 & $\mathbf{F}$ & 3 months & - & SI. 20 & SI. 10 & $\left\{\begin{array}{l}\text { Lente } \\
\text { Ultralente }\end{array}\right.$ & $\begin{array}{l}30 \\
10\end{array}$ & 2 months & Satisfactory \\
\hline z & 11 & 5 & $\mathbf{F}$ & 3 months & - & - & - & $\left\{\begin{array}{l}\text { Lente } \\
\text { Ultralente }\end{array}\right.$ & $\begin{array}{l}8 \\
5\end{array}$ & 3 months & Satisfactory \\
\hline & 15 & 10 & $\mathbf{M}$ & 2 months & - & - & - & Lente & 24 & 2 months & Satisfactory \\
\hline
\end{tabular}

* Indicates a change in dose in IZS since discharge from hospital, a reduction in all cases except No. 7.

No blood sugar studies were made until at least the third day after a change in insulin dosage. In four of the old cases re-stabilization was not complete before transfer to IZS, and two of the new cases were treated with IZS from the start. After discharge from hospital all the children were seen at first weekly until it was evident that control was being maintained.

\section{Results}

So far 15 children, between the ages of $4 \frac{1}{2}$ and 15 , have been studied. Four of these, aged $5 \frac{1}{2}, 6,10$ and 12, were new cases. Ten children have continued under observation as out-patients for periods exceeding three months, and four for two months.

In Table 1 are shown details of all the cases, and the results of our assessment of control by IZS in hospital and subsequently. The results in terms of

TABLE 2

ASSESSMENT OF CONTROL BY IZS IN HOSPITAL AND AT HOME

\begin{tabular}{|c|c|c|c|c|c|c|}
\hline & \multicolumn{6}{|c|}{ Control by IZS } \\
\hline & \multicolumn{3}{|c|}{ In Hospital } & \multicolumn{3}{|c|}{ At Home } \\
\hline & Total & $\begin{array}{c}\text { Satis- } \\
\text { factory }\end{array}$ & Poor & Total & $\begin{array}{c}\text { Satis- } \\
\text { factory }\end{array}$ & Poor \\
\hline $\begin{array}{l}\text { Old cases } \\
\text { New cases } \\
\text { All cases }\end{array}$ & $\begin{array}{r}11 \\
4 \\
15\end{array}$ & $\begin{array}{r}10 \\
4 \\
14\end{array}$ & $\begin{array}{l}1 \\
0 \\
1\end{array}$ & $\begin{array}{r}10 \\
4 \\
14\end{array}$ & $\begin{array}{r}8 \\
4 \\
12\end{array}$ & $\begin{array}{l}2 \\
0 \\
2\end{array}$ \\
\hline
\end{tabular}

total numbers are summarized in Table 2. It is convenient to consider the previously treated ('old') cases and the new untreated cases separately.

Old Cases (Total 11). Ten of these were previously maintained on two daily injections of soluble insulin, four of them with the addition of a small amount of protamine-zinc insulin in the morning or evening.

One of the old cases (No. 14) had been previously maintained on a single morning injection of mixed soluble and protamine-zinc insulin. In 10 of the 11 children the clinical control obtained in hospital with one daily injection of IZS was judged to be satisfactory. In one child (Case 13) it proved impossible to maintain adequate stabilization in hospital with IZS even after a protracted trial.

Ten of the 11 old cases have been observed as out-patients, eight for periods between four and five months, and two for two months. Of the 10, eight have remained well stabilized and no major alterations in their insulin dosage or diet have been necessary.

In the following three children we failed to achieve or to maintain satisfactory control with IZS:

(1) A boy aged 10 (Case No. 4) was previously on soluble insulin, 30 units in the morning, and 16 units plus 4 units of PZI in the evening. Since developing 
diabetes when aged 7 , he had proved particularly unstable and he had often been re-admitted to hospital with bouts of vomiting and ketonuria. He seemed well stabilized in hospital on Novo 'lente', 60 units, but two months after discharge was re-admitted with vomiting and ketonuria. After 36 hours of treatment with soluble insulin eight-hourly he had recovered, and Novo 'lente' insulin was resumed at its former dosage. Again, control seemed satisfactory. However, since then he has had two similar relapses, both beginning at home.

(2) A girl aged 15 (Case No. 6) was previously on soluble insulin, 40 units b.d., with PZI, 8 units, in the evening. Since puberty she had been difficult to keep stabilized and her insulin requirement had been increasing. On some days glycosuria was very heavy, and on others she suffered from hypoglycaemic symptoms. In hospital Novo 'lente', 100 units, daily, appeared to be the optimum dose, and control seemed better. However, after 10 weeks of observation as an out-patient, she was admitted to the adult wards of another hospital with a severe hypoglycaemic attack, which had occurred in the forenoon. Soluble insulin has been resumed.

(3) It had recently proved difficult to maintain stabilization with soluble insulin in a girl aged 14 (Case No. 13). Glycosuria was heavy and difficult to control without risk of hypoglycaemic symptoms. Despite prolonged trial of varying doses and proportions of amorphous and crystalline IZS, satisfactory control could not be maintained for more than a few days at a time without further changes in dose. She was rather better stabilized when soluble insulin twice daily was resumed. For either form of insulin her new requirement lay between 50 and 60 units daily.

New Cases (Total Four). Two of these children (Cases 7 and 10) were first brought under control with soluble insulin before IZS was begun. Both were satisfactorily controlled by IZS. Case 7 required a threefold increase in dosage during the first weeks after discharge from hospital, but has remained stable since then.

The other two new cases (Nos. 11 and 15), were treated from the start with IZS, preliminary soluble insulin not being used. Case 2 was given 'semilente' once daily (10 units) for a few days before 'lente' was begun. Case 15 was started immediately on one daily injection of 'lente' (15 units). In both children the initial response was good and satisfactory control was finally achieved with higher doses.

It may be mentioned that in these new cases the usual rapid gain in weight and return of well-being occurred. The disappearance of acetonuria and reduction in glycosuria was just as rapid in the cases treated initially with IZS as it was in the other two.

The histories of two children are given here as fairly typical examples of cases that have done well on IZS.
A.R., a girl aged 5, Case No. 11, was admitted on November 13, 1953, with a history of thirst, frequency of micturition and loss of weight for three months. On examination she weighed $35 \mathrm{lb}$. and looked thin, and there was heavy acetonuria and glycosuria. A study of spontaneous blood sugar variations showed a morning (fasting) level of $85 \mathrm{mg}$. \%, and levels between 240 and $340 \mathrm{mg}$. \% during the rest of the day. The four-hourly Benedict's tests on the urine were almost constantly 'orange'. Values of 31 and $19 \mathrm{~g}$. for 24-hour urinary sugar output were obtained before the administration of any insulin.

Treatment was then begun with single morning injections of Novo 'semilente' insulin, 10 units. A 1,700 calorie diet was given. Within three days urinary acetone disappeared and after six days urinary Benedict's tests assumed an almost constant pattern of green or blue by day and orange at midnight and at 4.0 a.m. Urinary sugar output fell to between 9 and $17 \mathrm{~g}$. a day. A 24-hour blood sugar study showed values below $155 \mathrm{mg} . \%$ for eight hours after the injection of 'semilente' insulin, and $350 \mathrm{mg} . \%$ at midnight. With 'lente', 10 units, the urinary sugar pattern remained the same, but a blood sugar curve showed a more rapid rise by day. On 'lente', 15 units, the blood sugar pattern was similar to that obtained with 'semilente', 10 units, with a midnight level of $265 \mathrm{mg}$. \%. A mixture of 'ultralente', 5 units, and 'lente', 8 units, gave daytime levels between 65 and $140 \mathrm{mg}$. \%, and $200 \mathrm{mg}$. \% at midnight. With all these varying doses she was free of ketosis and hypoglycaemic symptoms. She gained $5 \mathrm{lb}$. during her stay in hospital and was always very active.

She was allowed home on January 14, 1954, on Novo 'lente' insulin, 15 units daily in the morning. A month later the combination of 'lente' and 'ultralente' was resumed. She has remained well stabilized during the three months since she left hospital.

J.R., a girl aged $7 \frac{1}{2}$, Case No. 1 , had been a diabetic since the age of 5 . She was admitted for a trial of IZS on August 22, 1953, aged $7 \frac{1}{2}$, having been fairly well controlled for some time by soluble insulin, 15 units in the morning and 8 in the evening, and a diet giving about 1,700 calories. On examination she looked well, weighed $49 \mathrm{lb}$, and there were no abnormal physical findings apart from glycosuria, and induration at the sites of insulin injection. A 1,900 calorie diet was given. The previous dose of soluble insulin was found, under hospital conditions, to be inadequate, and it was raised to $25: 18$. After changing to Novo 'lente' insulin, a requirement of about 50 units was soon apparent. With 55 units hypoglycaemic attacks occurred between 4 and 5 a.m., low blood sugars were found at mid-day and 4 p.m., and the daily urinary sugar output ranged from 1.5 to $7 \mathrm{~g}$. On 50 units she remained free of hypoglycaemic symptoms and from ketonuria, although her urinary sugar output was sometimes rather high. Repeated 24-hour blood sugar studies showed lowest levels sometime between mid-day and 8 p.m. and highest levels at midnight. The curves obtained with two daily injections of soluble insulin had shown a similar shape 


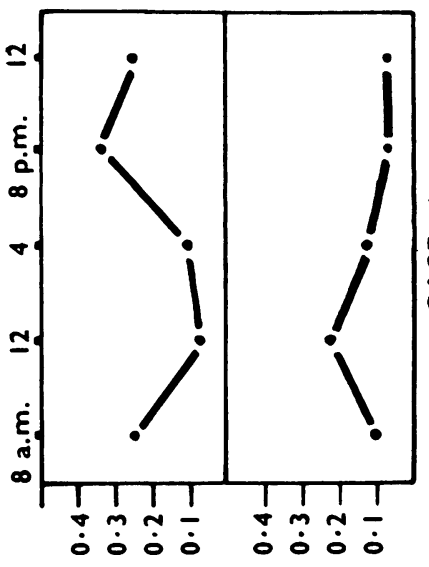

(.) $001 / \cdot 8)$ y

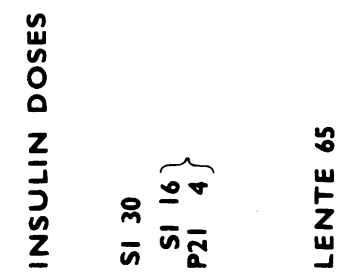

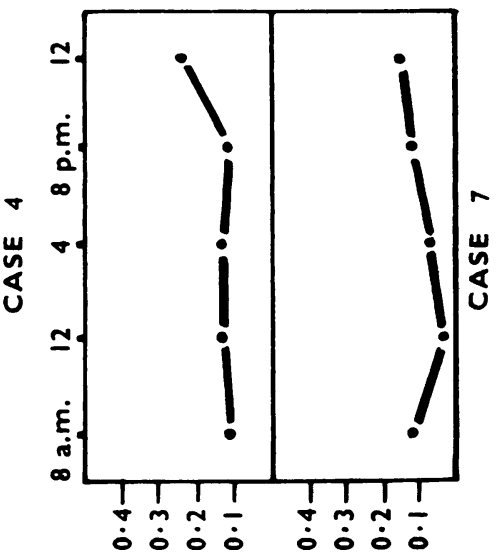

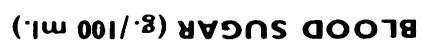

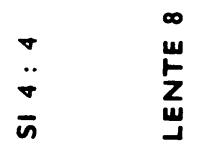

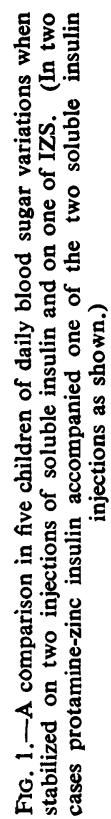

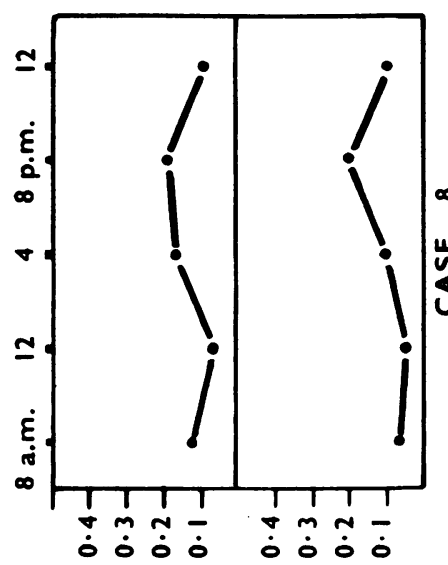

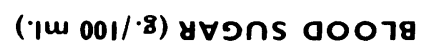

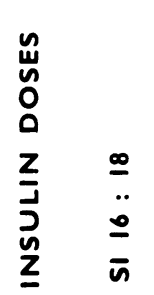

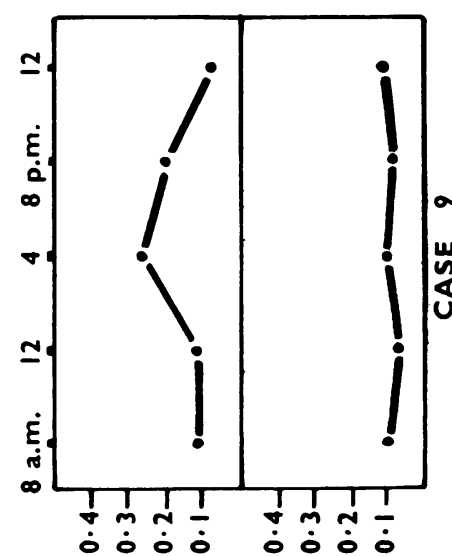

(j) $001 / .8)$ y
㞻

$\begin{array}{ll}\underline{z} & \stackrel{0}{2} \\ \vdots & \ddot{n} \\ \underline{n} & \bar{n}\end{array}$

$\underset{m}{m}$

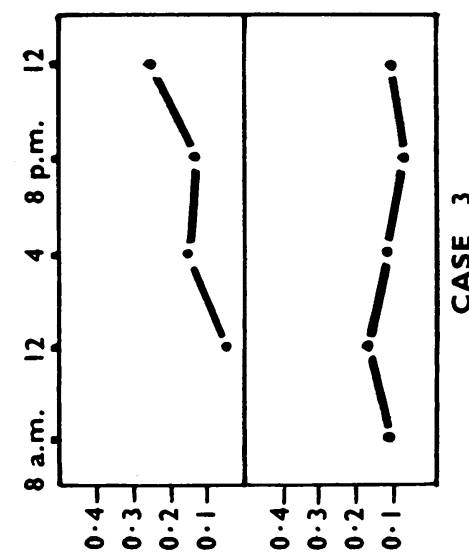

(') $001 / \cdot 8)$ y

$n$
$u$
$n$
0
0

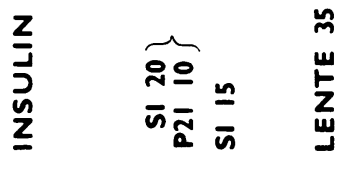


and range. During one period she developed acetonuria and heavy glycosuria, probably as a result of injecting her insulin into sites of marked local induration. During the month after her discharge home on October 23 the dose of Novo 'lente' had to be progressively dropped from 50 to 40 units to avoid mild symptoms of hypoglycaemia in the late afternoon. On the latter dose she has remained very well stabilized for five months.

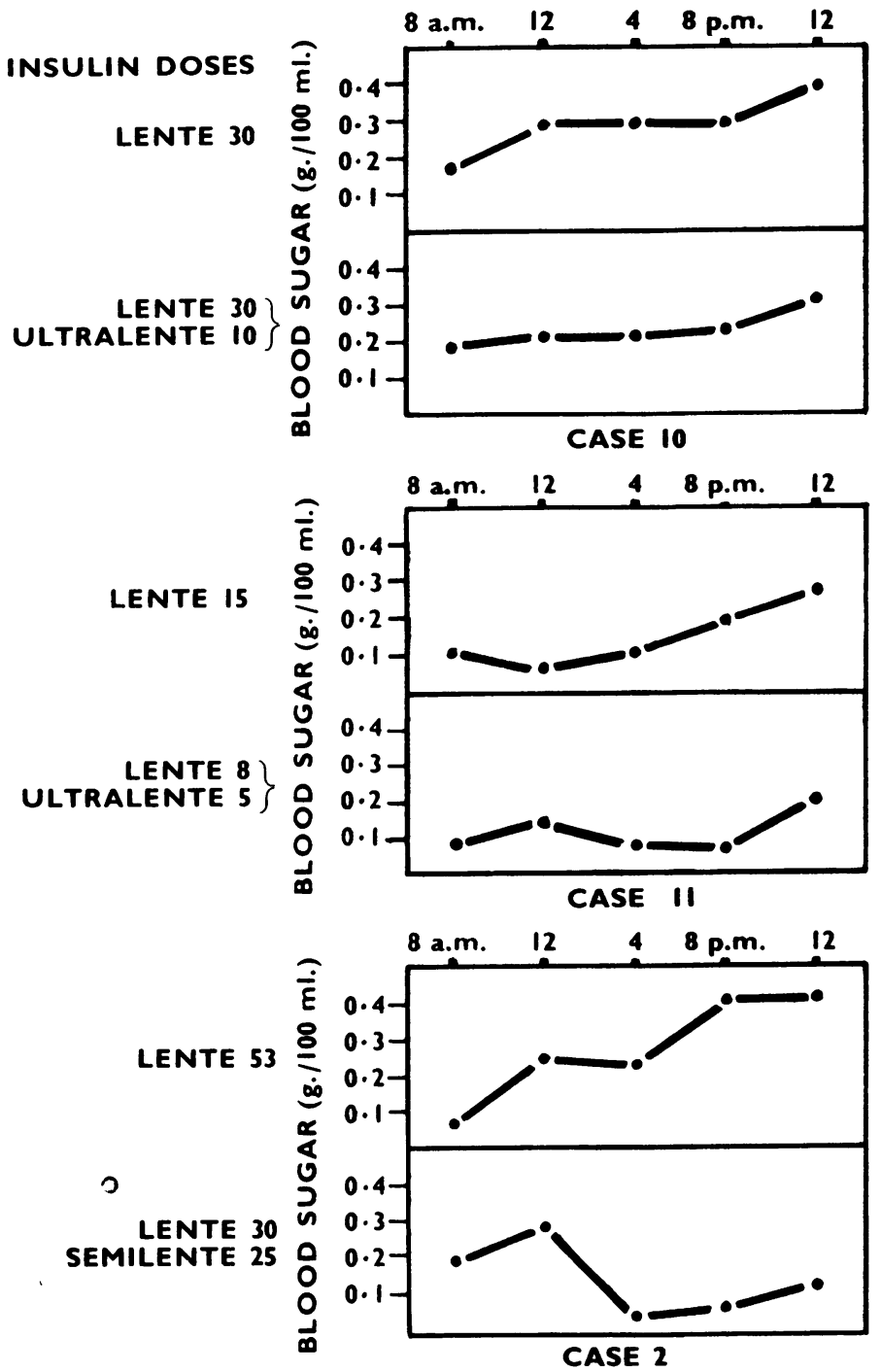

Fig. 2.-Examples of improved control of blood sugar obtained in three diabetic children by combining 'ultralente' (crystalline IZS) or 'semilente' (amorphous IZS) with IZS Novo 'lente.'

\section{Discussion}

During these studies the lability of diabetic children in terms of variations in urinary glucose loss and insulin requirement was often evident. Even when insulin dosage and calorie intake were kept constant, and in the absence of infection or of any known environmental change, considerable variations in the daily urinary sugar output occurred in individual children. Even in apparently stabilized children these variations in glycosuria were often of the order of $\pm 50 \%$. Apart from day-to-day variations, there was often a more gradual swing towards increased or diminished glycosuria, and to different insulin requirements. In ore case at least emotional factors appeared in some way to be operative.

These spontaneous variations could conceivably reflect changes in endogenous insulin production. The fact that two of our most unstable cases were girls at or near puberty may indicate the influence of changes in hormone balance on the insulin requirements of the body. Whatever the mechanisms of these changes, they produce, when insulin requirement is being studied, a 'shifting baseline', and make shortterm comparisons of different insulin preparations difficult and liable to fallacious interpretation. Bearing this in mind, however, our experience so far has enabled us to reach certain broad conclusions concerning the use of insulin zinc suspension in children.

Blood Sugar Levels. As judged by the range of the daily blood sugar variations, it has been possible, in all the nine children who were well stabilized before transfer, to obtain as good control with one injection of IZS as with two of soluble insulin. The cases used for this comparison are shown in Table 3. In three of them a small proportion of protamine-zinc insulin accompanied one of the soluble insulin injections. It should be stated that for any given patient the number of blood sugar studies done with IZS usually exceeded those done with soluble insulin, so that the picture obtained of blood sugar control with soluble insulin was probably the less complete. In most of the children the pattern of blood sugar changes varied in detail 
from day to day even with the same insulin dose, but for a given type of insulin a basic shape of curve tended to recur in each child. It was possible to modify this basic curve by varying the proportions of amorphous or crystalline insulin zinc suspension. In a small proportion of the children, those with the highest insulin requirements, the pattern of the blood sugar variation was inconstant, and these children proved the most difficult to stabilize. It would doubtless have been possible to alter the blood sugar patterns by variations in the dietary distribution of carbohydrate, but in these studies diets were kept constant to facilitate the comparison of insulin action.

Of the 14 children discharged from hospital on IZS, nine were on Novo 'lente' alone. In Fig. 1 examples are shown of satisfactory blood sugar control obtained with the 'lente' mixture, with, for comparison, blood sugar curves obtained in the same children by injections twice daily of soluble insulin, in some cases combined with protaminezinc insulin.

In three of the children, although 'lente' insulin gave good blood sugar control from 8 a.m. to 8 p.m., rather high midnight levels occurred. The addition of a proportion of the pure crystalline suspension ('ultralente') gave more prolonged control (Fig. 2). In the light of this experience it is possible that some of our earlier cases, stabilized on 'lente' alone, might have benefited from the addition or substitution of a proportion of 'ultralente'. Two of our cases were stabilized on a mixture of 'lente' and 'semilente'. In one of these 'lente' alone had repeatedly failed to prevent a rather steeply rising blood sugar level throughout the day (Fig. 2).

We have found, as similarly reported by others, a tendency for our cases on IZS to require a slightly higher dosage of insulin than previously (FitzGerald et al., 1954; Venning, 1954). Of nine patients who were well stabilized before transfer to IZS, six required an increase in total units for good control with IZS. The average increase was $15 \%$. In two cases the total was unchanged, and in one it was slightly less (Table 3 ).

Clinical Control. It has been possible to achieve satisfactory control with one injection of IZS in the majority of our cases, and so far to maintain good stabilization with the children leading normal lives at home. In four of the children adjustments have been made in insulin dosage or diet since they left hospital. Such adjustments must always be necessary in diabetic children if really good control is to be maintained, and will be needed with any insulin preparation.
TABLE 3

COMPARISON IN NINE CHILDREN OF TOTAL INSULIN REQUIRED DAILY FOR STABILIZATION BEFORE AND AFTER TRANSFER TO IZS

\begin{tabular}{|c|c|c|c|c|c|}
\hline \multirow{3}{*}{ Case No. } & \multicolumn{3}{|c|}{ Units Needed Daily } & \multirow[b]{3}{*}{ IZS } & \multirow{3}{*}{$\begin{array}{c}\% \text { Increase } \\
\text { or } \\
\text { Decrease }\end{array}$} \\
\hline & \multicolumn{3}{|c|}{ Before Transfer to IZS } & & \\
\hline & SI & PZI & Total & & \\
\hline $\begin{array}{r}1 \\
2 \\
3 \\
4 \\
6 \\
7 \\
8 \\
9 \\
10\end{array}$ & $\begin{array}{r}43 \\
49 \\
23 \\
46 \\
80 \\
8 \\
34 \\
34 \\
30\end{array}$ & $\begin{array}{l}- \\
5 \\
4 \\
8 \\
= \\
=\end{array}$ & $\begin{array}{r}43 \\
49 \\
28 \\
50 \\
88 \\
8 \\
34 \\
34 \\
30\end{array}$ & $\begin{array}{r}50 \\
50 \\
30 \\
60 \\
100 \\
8 \\
34 \\
32 \\
40\end{array}$ & $\begin{array}{l}+16 \\
+2 \\
+7 \\
+20 \\
+14 \\
= \\
=6 \\
+33\end{array}$ \\
\hline
\end{tabular}

$\mathbf{S I}=$ soluble insulin. $\quad \mathbf{P Z I}=$ protamine-zinc insulin.

It is noteworthy that those three children in whom we failed to maintain satisfactory control with IZS had all previously proved particularly difficult and unstable cases. Further, we cannot yet say finally whether these children are better controlled by the older insulin preparations than by IZS.

Our experience so far with insulin-zinc suspension has given us the general impression that its action is reliable and smooth. We have experienced no alarming episodes during transfer from other insulins to IZS. Hypoglycaemic symptoms, if they occurred, tended to be regular and predictable with a gradual onset. With the Novo 'lente' mixture, hypoglycaemic symptoms were commonest between 10 a.m. and 6 p.m., and in only one case did they occur in the early hours of the morning.

In children with severe ketosis and vomiting, and where there is a threat of diabetic coma, we have used frequent injections of soluble insulin, and we believe that soluble insulin must retain its place in the treatment of such crises.

Practical Considerations. There has been no evidence of loss of potency in IZS (Novo) while we have been using it. Under the low power of the microscope the cuboidal insulin-zinc crystals contained in 'lente' and 'ultralente' are easily seen. The number of crystals per cubic millimetre in two vials of 'lente' were estimated, using a red cell counting chamber. The crystal counts in the new vials and in the same vials when nearly empty after use in the ward showed no significant variation.

We have found it important in practice to think of the three preparations 'semilente', 'lente' and 'ultralente', in terms of the two basic components, viz. amorphous (shorter-acting) and crystalline (longer-acting) insulin zinc suspensions. Failure to do this resulted in our administering to one case a larger proportion of the amorphous form than was intended when adding 'semilente' to 'lente'. The 
graph recently published by Thorn (1954) has proved useful in this respect.

In none of our cases so far has a local inflammatory reaction occurred at the site of injection of IZS. The importance of varying the injection sites each day to ensure regular absorption was impressed on us by our experience with one case. While in hospital this child developed ketonuria for no apparent reason, until it was discovered that she was injecting all her 'lente' insulin into one of two indurated sites on her thighs. As soon as injections were given elsewhere, control was restored. It needs to be borne in mind that if insulin is given once daily smooth absorption is even more essential to the maintenance of control than it is when injections are more frequent.

\section{Conclusions}

From this short experience with a small number of cases it would be unjustifiable to draw anything but tentative conclusions. Nevertheless our findings have been encouraging enough for us to consider that insulin zinc suspension is likely to prove a reliable and effective long-acting insulin preparation. It appears probable that, by its use, reliable control could be maintained with a single daily injection in the majority of diabetic children.

\section{Summary}

A study has been made of insulin zinc suspension (IZS) in 15 diabetic children.

In 14 of the 15 children it proved possible to obtain satisfactory control in hospital with one daily injection of IZS. Fourteen of the children have been observed as out-patients, and 12 of them have remained well stabilized, though changes in the dosage have been needed in four of them.

In three of the children maintenance of control with IZS was poor, in one child while in hospital, and in two after returning home. All three had previously proved particularly unstable.

Four of the children were previously untreated and all of these were eventually well controlled by IZS. Two of them were treated initially with IZS and responded well.

In nine children blood sugar control with soluble insulin and with IZS was studied for comparison. The control obtainable with one daily injection of IZS was in all of them at least equal to that given by two injections of soluble insulin.

There has been no evidence of deterioration in the activity of IZS during the study, and no evident reactions have occurred at the sites of its injection.

It is suggested that the majority of diebetic children could probably be satisfactorily controlled by a single daily injection of insulin zinc suspension.

I wish to thank Professor A. V. Neale, Dr. John Apley and Dr. Beryl Corner for enabling me to carry out this clinical trial in children under their care, and for much help at all stages, including valuable criticism of this paper. Dr. G. K. McGowan kindly arranged special laboratory facilities for the Bristol cases, and $\mathrm{Mr}$. $H$. Donaldson did the majority of the blood sugar estimations; I am much indebted to both of them. I am also indebted to Dr. Rachel Douglas who carried out much of the clinical work in the early stages. I am grateful to Dr. J. H. Smith for help with the cases at the Royal United Hospital, Bath, and to the staff of the Biochemical Laboratory there.

Evans Medical Supplies Ltd., supplied the 'Novo' insulins before they were available generally.

\section{REFERENCES}

Collens, W. S. and Boas, L. C. (1946). The Modern Treatment of Diabetes Mellitus. Springfield, Ill

FitzGerald, M. G., Thorn, P. A. and Malins, J. M. (1954). Lancet, $1,187$.

Hallas-Møller, K., Jersild, M., Petersen, K. and Schlichtkrull, J. (1952). J. Amer. med. Ass., 150, 1667.

Lawrence, R. D. (1954). Brit. med. J., 1, 58.

Lawrence, R. D. (1954). Brit. med. J., 1, 58.

Murray, I. and Wilson, R. B. (1953). Ibid., 2, 1023.

Nabarro, J. D. N. and Stowers, J. M. (1953). Ibid., 2, 1027.

Thorn, P. A. (1954). Lancet, 1, 190.

Venning, G. R. (1954). Ibid., 1, 480. 